Hence the sum assured during the first year is $1000-678.067=$ 321.933 ; and the amount for each suceeding year is found by adding $678.067 \div 10=67 \cdot 807$ to that for the year preceding. The sum assured during the eleventh year is thus $\$ 1000$; and it remains at this amount during the rest of life.

The deduction at the outset seems here somewhat heavy; but it rapidly diminishes, and vanishes at the end of ten years. Were the term extended to twenty years the deduction at the outset would be only $365^{\circ} 053$, and the assurance would consequently commence at 634.947 .

I must defer till another opportunity the development of the schemes here shadowed forth. I will now merely mention, that they find their practical applications in cases in which it is arranged that a party who has been "rated up," instead of paying additional premium, shall be subjected to a temporary abatement of assurance.

$$
\begin{aligned}
& \text { I am, Sir, } \\
& \text { Your most obedient servant, }
\end{aligned}
$$

London, 21 Oct. 1872.

P. GRAY.

\title{
ON THE RELATION BETWEEN THE VALUE OF A POLICY AND THE RATE OF INTEREST.
}

\section{To the Editor of the Journal of the Institute of Actuaries.}

Sin,-In the paper on "Extra Premium," by Mr. J. R. Macfadyen, in the current volume of the Joumal, that gentleman has given, in a footnote on p. 89 , a demonstration intended to show that "in any given case it is practically certain that the value of a policy by a higher rate of interest must always be less than by a lower." Having, sometime ago, myself arrived at a similar result to $\mathbf{M r}$. Macfadyen's by a rather different process, I venture to send it you, with the hope that it may be of interest to some of your readers.

We have, by a well-known formula,

$$
{ }_{2} \nabla_{x}=1-\left(1-\nabla_{x}\right)\left(1-\nabla_{x+1}\right) \ldots .\left(1-V_{x+n-1}\right) ;
$$

consequently, it will be sufficient to consider how the value of a policy one year old is affected by increasing or diminishing the rate of interest at which it is calculated.

Now,

$$
\begin{aligned}
\mathrm{V}_{x} & =1-\frac{1+a_{x+1}}{1+a_{x}} \\
& =1-\frac{a_{x}}{v p_{x}\left(1+a_{x}\right)}
\end{aligned}
$$

or, omitting the subscript $x$,

$$
\mathrm{V}=1-\frac{a}{v p(1+a)}
$$

Differentiating this with respect to $v$, we have 


$$
\begin{aligned}
\frac{d \nabla}{d v} & =-\frac{1}{p} \cdot \frac{v(1+a) \frac{d a}{d v}-a(1+a)-a v \frac{d a}{d v}}{v^{2}(1+a)^{2}} \\
& =-\frac{1}{p} \cdot \frac{v \frac{d a}{d v}-a(1+a)}{v^{2}(1+a)^{2}} .
\end{aligned}
$$

Now,

$$
a=v p+v^{2}{ }_{2} p+v^{3}{ }_{3} p+\ldots \ldots
$$

where ${ }_{n} p=$ probability of $a$ living $n$ years.

$$
\begin{aligned}
\therefore \quad v \frac{d a}{d v} & =v p+2 v_{2}^{2} p+3 v_{3}^{3} p+\ldots \ldots \\
& =a_{x}+v p a_{x+1}+v_{2}^{2} p a_{x+2}+\ldots \ldots
\end{aligned}
$$

Also, $\quad a(1+a)=a_{x}+v p a_{x}+v_{2}^{2} p a_{x}+\ldots \ldots$

Hence, if $a_{x}$ is greater than $a_{x+3}, a_{x+2}, \ldots . ., i . e$, if the value of an annuity on $x$ 's life is greater than the value of an annuity on any life older than $x$,

then

$$
a(1+a)>v \frac{d a}{d v}
$$

that is, $\frac{d V}{d v}$ is a positive quantity: in other words, as $v$ increases so also does $V$. But as $v\left(=\frac{1}{1+i}\right)$ increases, $i$ diminishes; therefore the lower the rate of interest the greater is the value of a policy of one year's standing on $x^{3}$ s life.

Similarly; if $a_{x+1}$ is greater than $a_{x+2}, a_{x+3} \ldots \ldots, \nabla_{x+1}$ increases in value as the rate of interest diminishes; and generally, if the values of annuities on the lives $x, x+1, x+2, \ldots \ldots$ form a continually decreasing series, the value of a policy of one year's standing taken out at any age from $x$ upwards is greater the less the rate of interest. Whence it follows from (1) that ${ }_{n} V_{x}$ inereases as the rate of interest decreases.

$$
\text { I am, Sir, }
$$

Your obedient servant,

$$
\begin{aligned}
& 18 \text { Lincoln's Inn Fields, } \\
& 26 \text { August 1872. }
\end{aligned}
$$

W. SUTTON.

\section{ERRATUM.}

The last line on p. 4 of this volume is misplaced and should be carried over so as to be the last line on p. 8 . 